\title{
Analysis of boiling
}

\author{
N. I. Kolev \\ Siemens AG, Erlangen, Germany
}

\begin{abstract}
The paper demonstrates that more useful information can be extracted from the boiling analysis by consistently incorporating gross turbulence characteristics and appropriate local volume and time averaging.

Keywords: heat transfer, nucleate boiling, flow boiling.
\end{abstract}

\section{Introduction}

Common practice in thermal engineering today is to use empirical correlations for heat transfer. Advances in the knowledge like turbulence modeling in two phase flow, tracing the history of origination of bubbles, droplets etc., dynamic two-phase flow pattern recognition etc., require more information from the heat transfer models like haw to consider the deviation from the developed turbulence, haw to provide internal characteristics of boiling like bubble departure diameters and frequencies and others. This paper demonstrates that more information can be exhausted from the analysis by consistently incorporating even of gross turbulence characteristics in the analysis and appropriate local volume and time averaging.

\section{Single phase flow}

The well-known Dittus-Boelter empirical correlation [1] modeling single phase heat transfer in a pipe

$$
\frac{\dot{q}_{w l, \infty}^{\prime \prime} D_{h}}{\left(T_{w}-T_{l}\right) \lambda_{l}}=0.024 \operatorname{Re}^{0.8} \operatorname{Pr}_{l}^{0.4} .
$$

reproduces for instance [2] data with a mean error of 3\%, see Fig. 1a. 

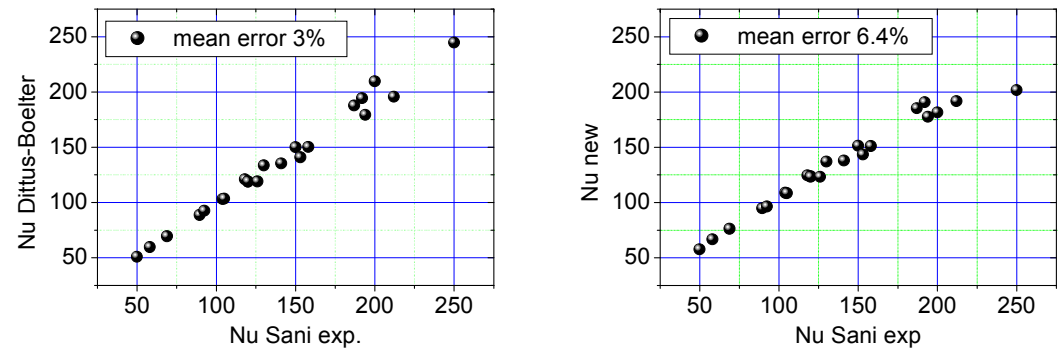

Figure 1: Predicted Nusselt number as a function of the computed: a) correlation [3]; b) small eddy wall renewal hypothesis using the blasius equation for the friction pressure loss. Data [2].

Imagine a flow behind a spacer grid in bundle where the turbulence jumps to a maximum and then decay along the flow. Improvement of the heat transfer behind the grid and then exponential decay to the developed heat transfer is experimentally observed in [3] p. 7-43. Empirical correlation was proposed in [3] but an attempt to link deterministically this phenomenon with flow parameters was not done so far. Kolev [4], simulating boiling in a BWR bundle, reported the changes in the specific turbulent kinetic energy of the liquid and its dissipation as shown on Fig. 2.
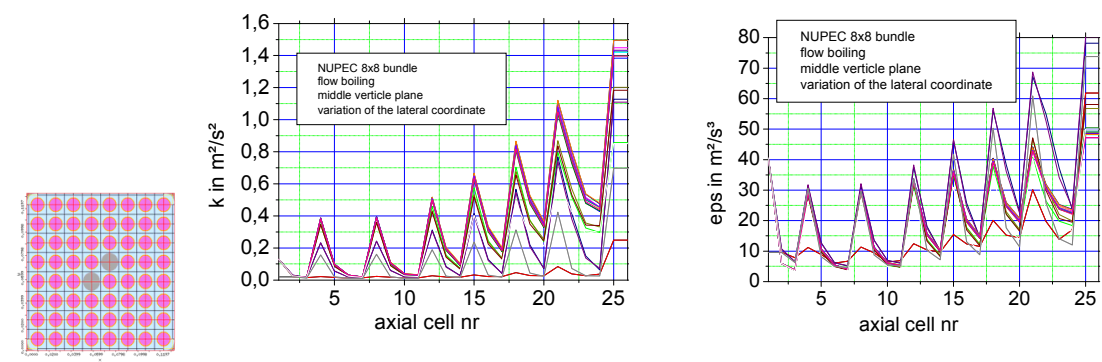

Figure 2: $\quad$ Bundle 1-1, 1 OECD/NRC Benchmark test problem no. 5, [4]: Turbulence of boiling liquid in rod bundle computed with IVA computer code, [4]. a) Turbulent kinetic energy as a function of the axial coordinate; b) Dissipation of the turbulent kinetic energy as a function of the axial coordinate.

The jumps, behind the spacer grids are clearly visible. Obviously, the improvement of the heat transfer behind the grids is somehow connected to the turbulence, but how? How to connect the heat transfer to the turbulence characteristics in this case is our first subject to be solved. This author will first derive the equivalent to the Dittus and Boelter correlation starting with the visualization that before jumping apart from the wall, the turbulent eddies stay at the wall during the time $\Delta \tau_{\mu e, l, \infty}$, and receive heat from the wall by heat 
conduction. Therefore, the average heat flux at the wall follows the analytical solution of the Fourier equation averaged over the period $\Delta \tau_{\mu e, l}$

$$
\dot{q}_{w l, \infty}^{\prime \prime}=\frac{1}{\Delta \tau_{\mu e, l, \infty}} \int_{0}^{\Delta \tau_{\mu e, l, \infty}} \dot{q}_{w l}^{\prime \prime}(\tau) d \tau=2\left(\frac{\lambda_{l} \rho_{l} c_{p l}}{\pi \Delta \tau_{\mu e, l, \infty}}\right)^{1 / 2}\left(T_{w}-T_{l}\right) .
$$

With this result the following ratio will be easily obtained

$$
\dot{q}_{w l}^{\prime \prime} / \dot{q}_{w l, \infty}^{\prime \prime}=\left(\Delta \tau_{\mu e, l, \infty} / \Delta \tau_{\mu e, l}\right)^{1 / 2} .
$$

Therefore, increasing the frequency of turbulence with respect to steady developed flow increases heat transfer by following a square root function.

This is the asked relation. For practical application the reader will find in [5]:

$$
\begin{gathered}
\Delta \tau_{\mu e, l, \infty}=D_{h}^{2} /\left[\pi\left(0.012 \mathrm{Re}^{0.8} \operatorname{Pr}_{l}^{0.4}\right)^{2} a_{l}\right], \\
\Delta \tau_{\mu e, l} \approx b \sqrt{\nu_{l} / \varepsilon_{l}} .
\end{gathered}
$$

The comparison of Eq. 2 in the form

$$
\frac{\dot{q}_{w l, \infty}^{\prime \prime} D_{h}}{\left(T_{w}-T_{l}\right) \lambda_{l}}=\frac{2^{3 / 4}}{\pi^{1 / 2} b^{1 / 2}}\left[\lambda_{f r}\left(1-y_{\lim }^{+} \sqrt{\frac{\lambda_{f r}}{8}}\right)\right]^{1 / 4} \operatorname{Re}^{3 / 4} \operatorname{Pr}_{l}^{1 / 2},
$$

derived in [5] p. 79 with data given on Fig. $1 \mathrm{~b}$ gives $b=98.32$ resulting in a mean error of $6.4 \%$ and increasing divergence for lower Prandtl numbers. Replacing Eqs. 4 and 5 in 3 results in

$$
\frac{\dot{q}_{w l}^{\prime \prime}}{\dot{q}_{w l, \infty}^{\prime \prime}}=\frac{D_{h}}{0.374 \operatorname{Re}^{0.8} \operatorname{Pr}_{l}^{0.4}}\left(\frac{\varepsilon_{l}}{a_{l}^{2} v_{l}}\right)^{1 / 4}
$$

\section{Two phase flow boiling}

Integrating Eq. 2 for two phase flow in a channel results in

$$
\frac{\dot{q}_{w c}^{\prime \prime} D_{h}}{\left(T_{w}-T_{c}\right) \lambda_{c}}=\frac{2^{3 / 4}}{\sqrt{\pi b}}\left[\frac{\lambda_{f r, c o} \Phi_{c o}^{2}}{\alpha_{c}}\left(1-\alpha_{c} y_{\lim , c o}^{+} \sqrt{\frac{\lambda_{f r, c o} \Phi_{c o}^{2}}{8}}\right)\right]^{1 / 4} \operatorname{Re}_{c o}^{3 / 4} \operatorname{Pr}_{c}^{1 / 2},
$$

[5] p. 83. Now let us build the ratio of the two-phase Nusselt number to the Nusselt number computed so that all the two phase mass flow consists of continuum only. The result is

$$
N u=\left(\frac{\Phi_{c o}^{2}}{\alpha_{c}} \frac{1-\alpha_{c} y_{\lim , c o}^{+} \sqrt{\frac{\lambda_{f r, c o} \Phi_{c o}^{2}}{8}}}{1-y_{\lim }^{+} \sqrt{\frac{\lambda_{f r, c o}}{8}}}\right)^{1 / 4} N u_{c o} \approx\left(\frac{\Phi_{c o}^{2}}{\alpha_{c}}\right)^{1 / 4} N u_{c o} .
$$


Here the Nusselt number $N u_{c o}$ was computed assuming that the effective Reynolds number is computed so that all the two phase mass flow possesses the properties of the continuum $\operatorname{Re}_{c o}=D_{h}(\rho \bar{w}) / \eta_{c}$.

We immediately recognize that the increase of the turbulence leading to increase of the friction pressure drop is responsible for the increased heat transfer from or to the wall in the two phase flow region. Here $\Phi_{c o}^{2}$ is the Martinelli-Nelson multiplier.

Assuming a superposition of convective heat transfer and nucleate boiling as already done by many other authors results in $h_{\text {total }} \approx \sqrt{h^{2}+h_{\text {boiling }}^{2}}$, where $h \approx\left(\Phi_{c o}^{2} / \alpha_{c}\right)^{1 / 4} h_{c o}$.

The success of such approach depends on the accuracy of the two-phase pressure drop ratio. From Sani's experiment [2] this author obtain

$$
\Phi_{2 o}^{2}=1519.69039 \exp \left(-X_{t t} / 0.07719\right)+167.21358 \exp \left(-X_{t t} / 0.5413\right),
$$

see Fig. 3a. Using for the nucleate boiling mode that will be discussed in the next chapter, [5], and the slightly corrected theoretical result

$$
N u \approx\left(\Phi_{c o}^{2}\right)^{0.35} N u_{c o}
$$

results in mean averaged error of $11 \%$ compared to the Sani's data [2]. Note, that the contribution of the forced convection in convection boiling is substantial as shown in Fig. 3b. Once again, this correlation can be additionally corrected due to existing of non-developed turbulence after spacer grids.
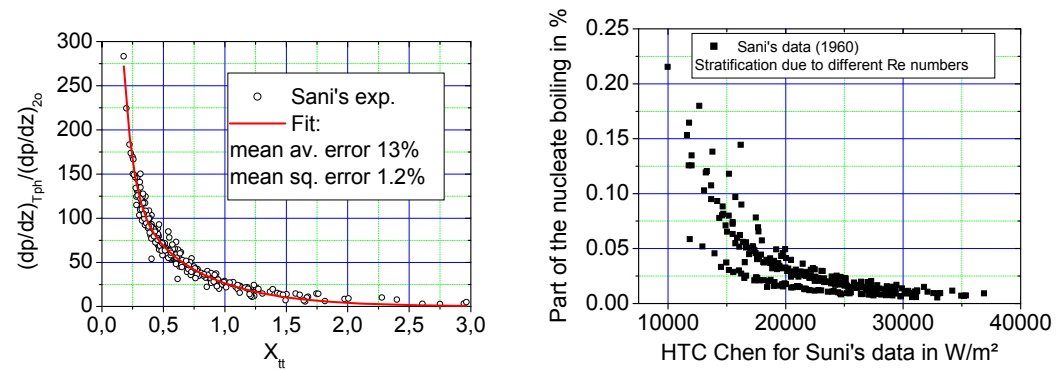

Figure 3: a) Friction pressure drop gradient divided by the friction pressure drop gradient computed if the total mass is flowing through the channel with liquid properties as a function of the Martinelli parameter: b) The part of nucleate boiling in flow boiling experiments performed by [2] computed with Chen's model [6]. 


\section{Droplet deposition and local turbulence}

Droplets deposition mass flow rate $(\rho w)_{32}$, known to be a function of the fluctuation velocity $u_{1}^{\prime}$ of the carrying steam

$$
(\rho w)_{32}=\frac{1-\chi}{1+\chi} \sqrt{\frac{2}{\pi}}\left(1-e^{-\Delta \tau / \Delta \tau_{13}}\right) u_{1}^{\prime} \rho_{3 c},
$$

[5] p. 172, influences dry out location. Here $\chi$ is Zaichik's reflection coefficient, $\Delta \tau_{13}$ is the particle relaxation time. It is obvious that

$$
\frac{(\rho w)_{32}}{(\rho w)_{32, \infty}} \approx \frac{u_{1}^{\prime}}{u_{1, \infty}^{\prime}} \approx \sqrt{\frac{k_{1}}{k_{1, \infty}}} .
$$

Therefore, increasing the turbulent kinetic energy of the continuum with respect to the steady developed flow, increases droplet deposition by following a square root function.

\section{Internal characteristics of boiling}

\subsection{Bubble departure diameter}

The bubble departure diameter at nuclide boiling is an important characteristic of the boiling process. It defines the bubble birth in a flow, influences flow and heat transfer characteristics. That the analytical description is a challenging problem is demonstrated on Fig. 4 where many theories are compared with data for water at atmospheric conditions and horizontal polished surface. When coupling the

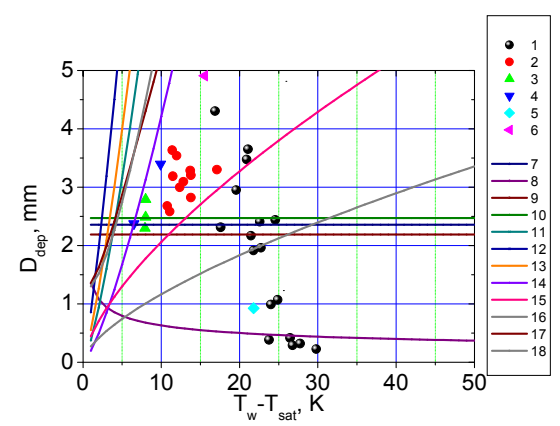

Figure 4: Bubble departure diameter as a function of superheating. Saturated water pool boiling at $0.1 \mathrm{MPa}$ pressure. For data sources and models used see [5, p. 418]. 
acting forces in the momentum equations for normal and perpendicular directions with heat conduction into the liquid, the result is the following expression defining the bubble departure diameter

$$
\left(D_{1 d} / D_{1 d, n c}\right)^{3}+\left(D_{1 d} / D_{1 d, f c}\right)^{2}=1,
$$

$[5$, p. 424,7$]$. Here $D_{1 d, n c}$ and $D_{1 d, f c}$ are bubble departure diameters for natural or forced convection only. The predictions in Figs. 5 and 6 demonstrate the progress regarding the state of the art.
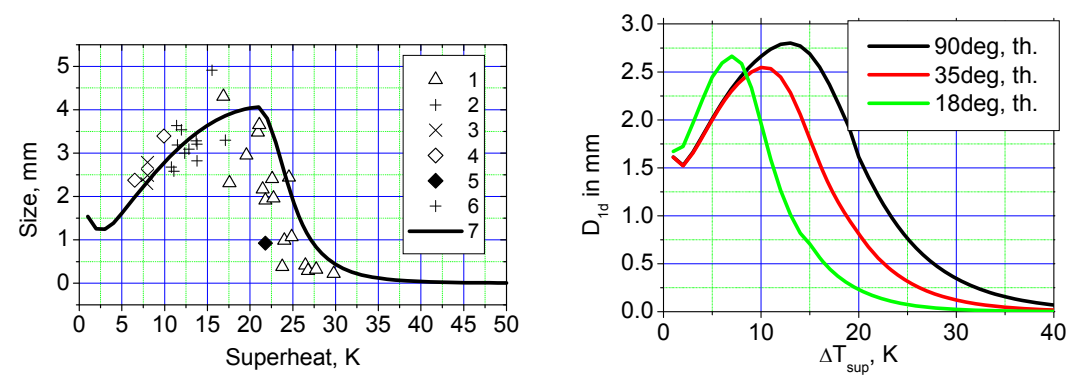

Figure 5: a) Bubble departure diameter as a function of superheating. Saturated water pool boiling at $0.1 \mathrm{MPa}$ pressure. For data sources used see [5, p. 426]; b) Bubble departure diameter as a function of the superheat. Parameter: wetting angle.
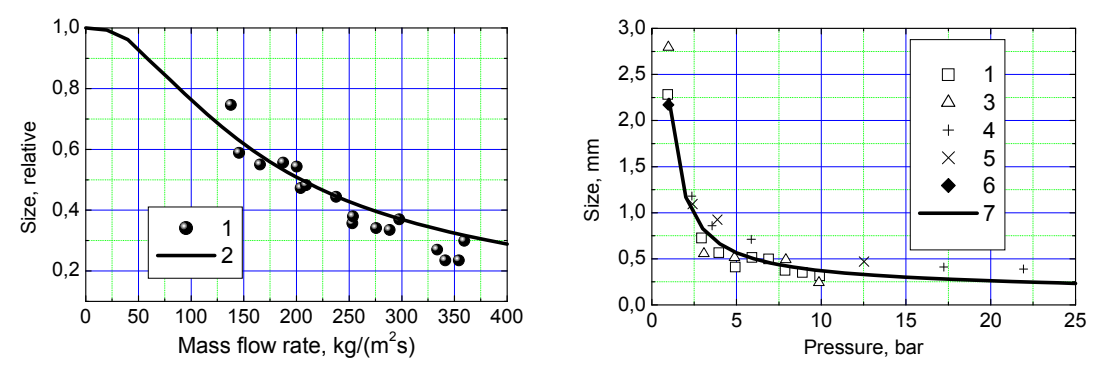

Figure 6: a) Bubble departure diameter as function of mass flow rate. Saturated water flow boiling at $0.1 \mathrm{MPa}$ pressure. $\mathrm{D}_{\text {hy }}=0.019 \mathrm{~m}$, $\mathrm{T}_{\mathrm{w}}-\mathrm{T}_{2}=15 \mathrm{~K} .1$ For data sources used see [5, p. 426]; b) Bubble departure diameter as a function of pressure. Saturated water pool boiling, superheat $=7.2 \mathrm{~K}$. Data of Tolubinsky and Ostrovsky: 1 Permalloy, 2 brass, 3 copper. Data of Semeria: 4 wire D $=0.8 \mathrm{~mm}$, 5, 6 plate. 7 Model. For data sources used see [5, p. 427]. 
The decreasing part after a maximum in Fig. 5a, data by Gaertner [8], can only be explained with a mutual bubble interaction shear force introduced into the momentum equation.

Neglecting this force causes monotonic increase of bubble departure size with increasing wall temperature difference which is the opposite of the experimentally observed trend. Water subcooling influences the maximum of bubble departure diameter as seen in Fig. 7. It is interesting to see that the theory gives a specific superheating value for a given sub-cooling at which bubbles can detach from a wall. At lower superheats we have the so called regime of the sliding bubbles. Knowing the bubble departure diameter and the law of bubble growth, the time for bubble growth $\Delta \tau_{1 d}$ until departure is easily computed. With the waiting time $\Delta \tau_{1 w}$ until the bubble starts to grow, Han and Griffith [9], the bubble departure frequency is $f_{1 w}=1 /\left(\Delta \tau_{1 d}+\Delta \tau_{1 w}\right)$. This is an important characteristic influencing the heat flux at the wall but also the turbulence generation due to bubble generation.

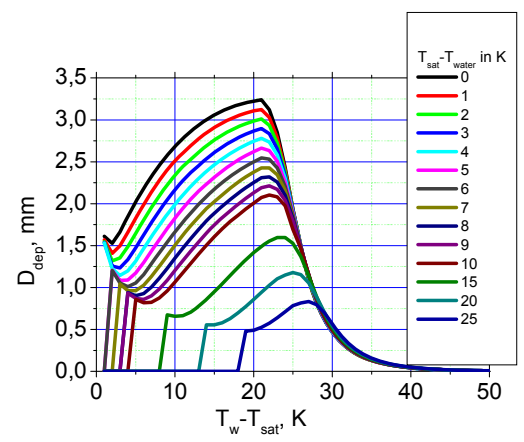

Figure 7: Bubble departure diameter at horizontal surface without flow as function of the wall superheating at 1bar. Parameter - water subcooling. Stagnant liquid.

\subsection{Turbulence generation due to nucleated boiling}

Boiling at hot surfaces can substantially modify the turbulence in the boundary layer depending on the bubble departure diameter. Because the bubble departure diameter $D_{1 d}$ is inversely proportional to the square of the velocity, with increasing velocity the diameter decreases. For bubble departure diameters comparable or larger than the viscous sub-layer the influence is important. This author identifies two mechanisms producing turbulence in this case: a) The expansion work of a single bubble in $\mathrm{W} / \mathrm{m}^{3}$ is

$$
\frac{\pi}{6} D_{1 d}^{3} \frac{1}{\rho_{2}}\left(1-\frac{\rho^{\prime \prime}}{\rho_{2}}\right)\left[p^{\prime}\left(T_{2}\right)-p\right],
$$


[10], being introduced into the surrounding liquid; b) The work for displacement of the surrounding liquid after the bubble departure in $\mathrm{W} / \mathrm{m}^{3}$ is

$$
\frac{\pi}{6} D_{1 d}^{3}\left(V_{21}^{d}\right)^{2} \frac{1}{4}
$$

[10], with a virtual mass coefficient equal to $1 / 2$. Given the heat perimeter $\Pi$ of the channel over the section $\Delta z$ the total amount of turbulence production per unit volume within a boundary layer with thickness $\delta$ is

$$
\rho_{2} P_{2}^{w, b o i l i n g}\left[\frac{W}{k g}\right]=\frac{f_{1 w} n_{1 w}^{\prime \prime}}{\delta} \rho_{2} \frac{\pi}{6} D_{1 d}^{3}\left\{\left(1-\frac{\rho^{\prime \prime}}{\rho_{2}}\right) \frac{1}{\rho_{2}}\left[p^{\prime}\left(T_{2}\right)-p\right]+\frac{1}{4}\left(V_{21}^{d}\right)^{2}\right\} \text {. }
$$

Here $f_{1 w}$ is the bubble departure frequency.

\subsection{Heat transfer in nucleate boiling}

Now we realize that the turbulence generated by the bubble departure is an important mixing mechanism influencing the boiling heat transfer. Before detach away from the wall, the turbulent eddies stay at the wall during the time $1 / f_{1 w}^{t}$ and receive heat from the wall by heat conduction. Therefore, the average heat flux at the wall follows again the analytical solution of the Fourier equation averaged over the period $\Delta \tau=1 / f_{1 w}^{t}$

$$
\begin{aligned}
\dot{q}_{w 2, n b}^{\prime \prime}(\Delta \tau) & =\frac{1}{\Delta \tau} \int_{0}^{\Delta \tau} \dot{q}_{w}^{\prime \prime}(\tau) d \tau=2\left(\frac{\lambda^{\prime} \rho^{\prime} c_{p}^{\prime}}{\pi \Delta \tau}\right)^{1 / 2}\left(T_{w}-T_{2}\right) \\
& =\frac{2}{\pi^{1 / 2}}\left(f_{1 w}^{t} a^{\prime}\right)^{1 / 2} \rho^{\prime} c_{p}^{\prime}\left(T_{w}-T_{2}\right)
\end{aligned}
$$

The idea to use the time-averaged heat flux at the wall stems from [20].

In contrast to these authors the turbulence renewal period rather than the bubble departure time is used here.

The time- and space-averaged pulsation velocity is then

$$
\overline{\bar{V}}_{2}^{\prime}=\left(B^{2} / D_{2, \text { inf }}\right) \frac{\Delta \tau_{d}}{\Delta \tau_{w}+\Delta \tau_{d}}=\frac{1}{0.84} B^{2} n_{1 w}^{\prime \prime}{ }^{1 / 2} \frac{\Delta \tau_{1 d}}{\Delta \tau_{1 w}+\Delta \tau_{1 d}} .
$$

The derivation was first published in [11], see also [10, p.448]. Here $n_{1 w}^{\prime \prime}$ are the active nucleation sides and $B^{2}=2 R_{1} d R_{1} / d \tau$ turns out to be a property of the local thermal condition for thermal controlled bubble growth, see Appendix 13.1 in $[10$, p.386]. The above time- and space-averaged pulsation velocity is in fact the space-averaged micro-convection velocity, first computed in [12], see also 
$[13$, p. 12], which is then time averaged. The fluctuation frequency is therefore a function of the bubble departure frequency

$$
f_{1 w}^{t}=\overline{\bar{V}}_{2}^{\prime} / \ell_{2}^{t}=\frac{1}{0.84} B^{2} n_{1 w}^{\prime 1 / 2} \frac{\Delta \tau_{1 d}}{\Delta \tau_{1 w}+\Delta \tau_{1 d}} / \ell_{2}^{t}
$$

but is not identical with it. Substituting Eq. (19) in (17) this author obtain in [11]

$$
\dot{q}_{w 2, n b}^{\prime \prime}=c_{1}\left(\frac{\lambda^{\prime} \rho^{\prime} c_{p}^{\prime}}{\ell_{2}^{t}\left(1+c_{2} \Delta \tau_{1 w} / \Delta \tau_{1 d}\right)}\right)^{1 / 2} n_{1 w}^{\prime \prime}{ }^{1 / 4} B\left(T_{w}-T_{2}\right)
$$

Here $c_{1}=2 /(\pi 0.84)^{1 / 2}$ is of order of unity. For the data comparison the value of $c_{1}=1.4626$ was used. Because $\Delta \tau_{1 w}$ is a very rough estimate for the average waiting time and therefore the ratio $\Delta \tau_{1 w} / \Delta \tau_{1 d}$ is only approximately analytically known, we introduce a empirical constant that has to be close to unity in $c_{2} \Delta \tau_{1 w} / \Delta \tau_{1 d}$. It turned out from comparison with data that $c_{2}=0.7$ [14].

First of all Eq. 20 demonstrates, that it is impossible to predict boiling heat transfer without knowing the nucleation characteristics of the specific surfaces. This is exactly what makes the prediction of boiling so difficult. But if this function is known, as it is the case with the data of Wang and Dhir, and is well approximated as demonstrated in Fig. 8, the prediction of Eq. 20 as given in Fig, $9 \mathrm{a}$ is astonishing. It not only discriminates the cases with different wetting angle for the boiling heat transfer (the larger wetting angle the better the boiling heat transfer), but inherently predicts critical heat flux (the larger wetting angle the smaller the CHF), and a mechanism which looks like a transition boiling. The effect of not performing a time averaging of the heat flux is demonstrated in Fig. $9 \mathrm{~b}$. For the finally obtained equation the most unexpected effect introduced by the additional time averaging by considering the mutual bubble interaction is the capability to predict the critical heat flux.

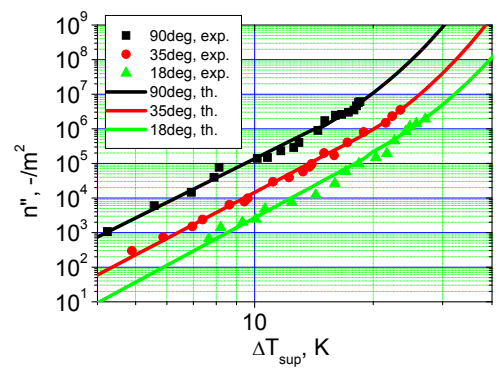

Figure 8: Active nucleation site density as a function of the superheat. Comparison: best fit with Wang and Dhir's primary data [14]. 

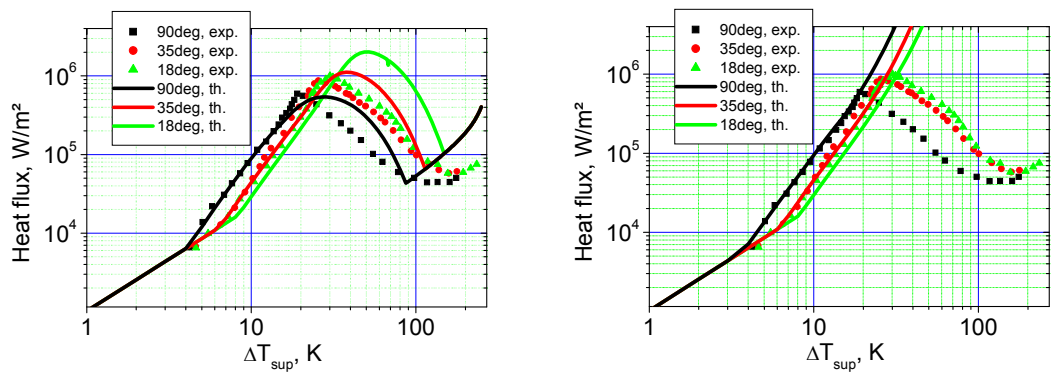

Figure 9: a) Heat flux as a function of the wall superheat: Prediction in [15] data by Eq. 20. Parameter: wetting angle. Best fit of the nucleation data as given in Fig. 10 [14]; b) Wang and Dhir experimental data for heat flux as a function of superheat for saturated water at 0.1 $\mathrm{MPa}$ and for three different static contact angles: 1) $90 \mathrm{deg}$; 2) 35 deg; and 3) 18 deg. 4), 5), 6) Prediction of the new theory for the corresponding static contact angles without taking into account the time averaging that is with $\mathrm{c} 2=0[14]$.
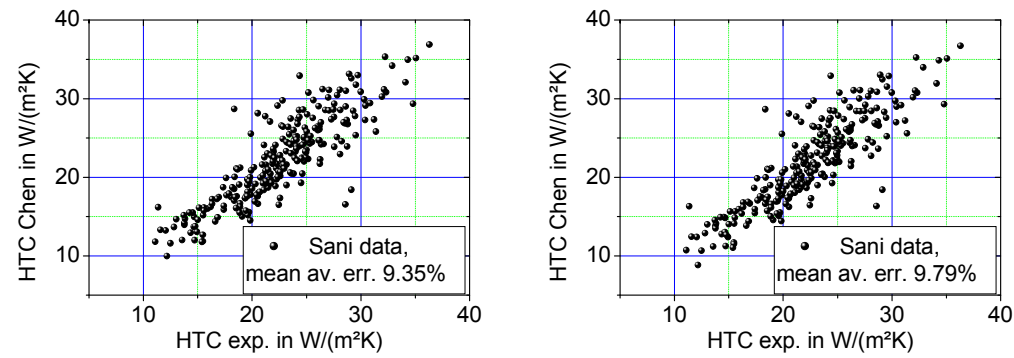

Figure 10: a) Comparison between Chen correlation with Forster and Zuber [12] nucleate boiling model and the data by [2]; b) Comparison between the Chen correlation [6] with Kolev [14] nucleate boiling model.

The performance of Eq. 20 within the Chen's flow boiling model is given in Fig. 10. This author's recommendation to use in $h_{\text {total }} \approx \sqrt{h^{2}+h_{\text {boiling }}^{2}}$ Eqs. (11) and (20) is not because it will change the good performance of the Chen correlation, but because this approach predicts internal characteristics of the flow each of it validated by experiment analytically. This is important for the future use in multiphase CFD where details about the flow field generation have to be also predicted by constitutive relation as summarized in this paper. 


\subsection{Film boiling on a vertical surface at mixed convection}

Film boiling at vertical surface, Fig. 11, at mixed convection is well described by integrating the mass momentum and energy conservation equations over a single cycle of instability wave length. The averaged film boiling heat transfer coefficient obtained by this author in [16] is

$$
\begin{gathered}
h=\frac{\dot{q}_{F B}^{\prime \prime}}{\Delta T_{s p}}=h_{n c}\left[\left(r^{*}+1\right)^{1 / 2}+2 r *\right]\left[\left(r^{*}+1\right)^{1 / 2}-r^{*}\right]^{1 / 2} . \\
h_{n c}=c_{n c}\left[\frac{\lambda_{1}^{3} \rho_{1} \Delta h \Delta \rho g}{\Delta T_{s p} \eta_{1} \Delta z} f_{n c}\right]^{1 / 4}, h_{f c}=c_{f c}\left[\frac{\rho_{1} \lambda_{1} \Delta h w_{2}}{\Delta T_{s p} \Delta z} f_{f c}\right]^{1 / 2},
\end{gathered}
$$

where $c_{n c}=2 / 3$, and $c_{f c}=1$ and

$$
r^{*}=\frac{1}{2}\left(\frac{h_{f c} c_{n c}}{h_{n c} c_{f c}}\right)^{2}=\frac{1}{2}\left(\frac{\rho_{1}}{\Delta \rho} \frac{P r_{1}}{S p} \frac{f_{f c}^{2}}{f_{n c}}\right)^{1 / 2} F r_{2},
$$
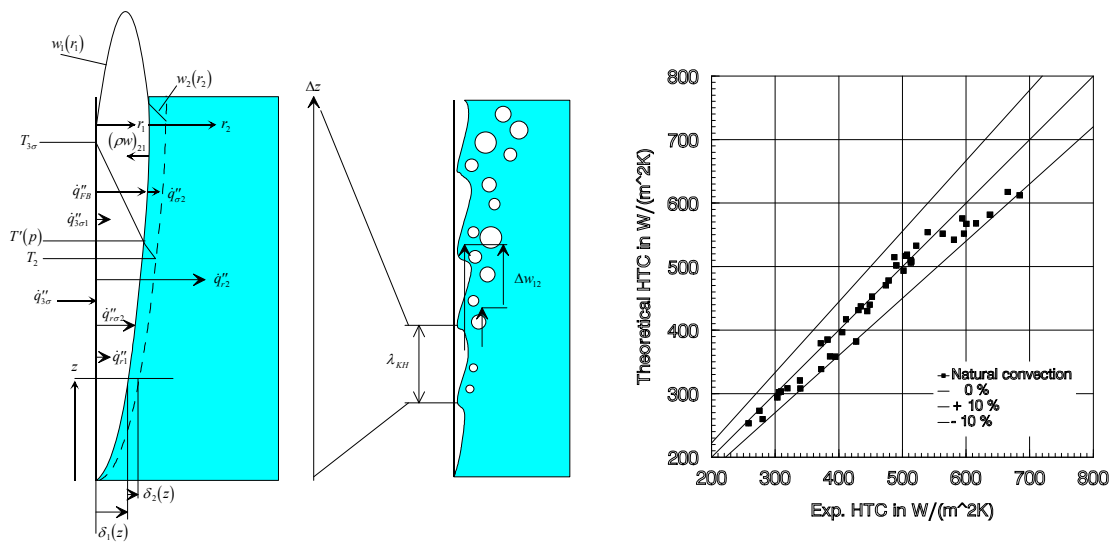

Figure 11: a) Geometry definition for film boiling on vertical wall. b) Instability of film boiling [16]; c) Comparison between the film boiling model and the data base of the KTH - Sweden, Okkonen et al. [17] Vaeth's radiation model [18] incorporated. $1.5 \mathrm{~m}$ vertical wall. Water at atmospheric pressure and subcooling 3 to 42 . Wall superheat 487 to $1236 \mathrm{~K}$.

On how to compute the different parameters as a function of the local conditions especially the vapor/liquid boundary layer thickness ratio $\xi$, see [10] p. 536. When liquid velocity is equal to zero, $r^{*}=0$, the expected solution $h=h_{n c}$ is obtained. Equation (21) was an important new result in 1998. This represents the average heat transfer coefficient for mixed convection as a function of the average flow properties, the heat transfer coefficient for natural 
convection and the Froude number. The accuracy of this equation is demonstrated in Fig. 14 where the prediction of the data from [17] was within $10 \%$ error band. The method was analytically validated for a second time in [19] and extended to hot jet heat transfer.

\section{Conclusions}

This paper demonstrates that more information can be extracted from the analysis by incorporating even of gross turbulence characteristics consistently in the analysis and appropriate local volume and time averaging. The main findings are:

1) Even in large scale analysis, the steady and transient averaged turbulence characteristics are necessary to increase the quality of predicting heat and mass transfer. It allows simulating the heat transfer change behind spacer grids analytically which is not the practice up to now.

2) This allows also simulating the change of the deposition behind the spacer grid and therefore brings us closer to the mechanistic prediction of dry-out.

3) Accurate boiling heat transfer predictions require knowledge on the nucleation characteristics of each particular surface.

4) Bubble departure diameter prediction in combined convection needs consideration of the mutual bubble interaction in any case. Otherwise, the experimentally observed decrease of the bubble departure size with the increasing wall superheating cannot be predicted.

6) The bubble departure at the surface modifies the turbulence structure of the flow by generating additional turbulence in the boundary layer.

7) Local time and surface averaging of the removed heat flux over characteristic pulsation cycles is a useful idea working for different heat transfer regimes: single phase flow behind grids, two phase flow, two-phase flow behind grids, pool and flow boiling, film boiling.

8) The pulsation characteristics at the wall controlling the heat transfer are associated with the bubble departure frequencies but not identical with them, considering the mutual interactions of the bubbles lead to a surprising analytical prediction of the departure from nucleate boiling just by using the mechanisms acting in flow boiling only.

9) The performance of the author's analytical two-phase convection model combined with its analytical nuclide boiling model is proven to have the accuracy of the empirical Chen's model by having the advantage of predicting analytically the internal characteristics of the flow each of it validated by experiment. This is also important for the future use in multiphase CFD where details about the flow field generation have to be also predicted by constitutive relation as summarized in this paper. 


\section{NOMENCLATURE}

$\begin{array}{ll}\begin{array}{ll}\text { Latin } \\ a\end{array} & \text { thermal diffusivity, } \mathrm{m}^{2} / \mathrm{s} \\ B^{2} & =2 R_{1} d R_{1} / d \tau, \text { bubble } \\ & \text { growth parameter, } \mathrm{m}^{2} / \mathrm{s} \\ c_{p} & \begin{array}{l}\text { specific capacity at constant } \\ \text { pressure, } \mathrm{J} /(\mathrm{kgK})\end{array} \\ D_{h} & \text { hydraulic diameter, } \mathrm{m}\end{array}$

$D_{1 d} \quad$ bubble departure diameter, $\mathrm{m}$

$D_{1 d, n c} \quad$ bubble departure diameters for natural convection only, $\mathrm{m}$

$D_{1 d, f c} \quad$ bubble departure diameters for forced convection only, $\mathrm{m}$

$\mathrm{Fr}_{2} \quad=\frac{w_{2}}{\sqrt{\Delta z g}}$, Froude number for vertical plane, -

$f_{1 w}^{t} \quad=\overline{\bar{V}}_{2}^{\prime} / \ell_{2}^{t}$ boundary layer turbulence fluctuation frequency, $1 / s$

$g$ gravity acceleration, $\mathrm{m} / \mathrm{s}^{2}$

$h$ heat transfer coefficient, $\mathrm{J} /\left(\mathrm{m}^{2} \mathrm{~K}\right)$

$h \quad$ specific enthalpy, $\mathrm{J} / \mathrm{kg}$

$\mathrm{Nu} \quad$ Nusselt number, -

$\operatorname{Pr} \quad=\eta /(\rho a)$, Prandtl number, -

$p \quad$ pressure, $\mathrm{Pa}$

$\dot{q}_{w l, \infty}^{\prime \prime} \quad$ time averaged heat flux at the wall into the liquid $l, \mathrm{~W} / \mathrm{m}^{2}$

$\dot{q}_{w l}^{\prime \prime} \quad$ instant heat flux at the wall into the liquid $l, \mathrm{~W} / \mathrm{m}^{2}$

$\mathrm{Re} \quad$ Reynolds number, -

Sp $\quad=c_{p 1} \Delta T_{s p} / \Delta h$, superheat number, -

$T_{w} \quad$ wall temperature, $\mathrm{K}$

$T$ temperature, $\mathrm{K}$
$D_{2, \text { inf }} \quad$ averaged distance between two adjacent active nucleation sites, $\mathrm{m}$

$n_{1 w}^{\prime \prime} \quad$ active nucleation sides, $1 / \mathrm{m}^{2}$

$u_{1}^{\prime} \quad$ fluctuation velocity of the carrying steam, $\mathrm{m} / \mathrm{s}$

$V_{21}^{d} \quad$ relative velocity between liquid and bubble, $\mathrm{m} / \mathrm{s}$

$\overline{\bar{V}}_{2}^{\prime} \quad$ time- and space-averaged pulsation velocity, $\mathrm{m} / \mathrm{s}$

$\begin{array}{ll}w & \text { velocity, } \mathrm{m} / \mathrm{s} \\ X_{1, \text { eq }} & \text { equilibrium steam mass flow }\end{array}$ ratio, quality, -

$X_{t t}=\left(\frac{\rho^{\prime \prime}}{\rho^{\prime}}\right)^{0.5}\left(\frac{\eta^{\prime}}{\eta^{\prime \prime}}\right)^{0.1}\left(\frac{1-X_{1, e q}}{X_{1, e q}}\right)^{0.9}$,

Martinelli-Nelson parameter,

$y \quad y$-coordinate, distance from the wall, $\mathrm{m}$

$y_{\lim } \quad$ virtual distance from the wall in which almost all the viscous dissipation is lumped, $\mathrm{m}$

$y_{\lim }^{+} \quad$ virtual distance from the wall in which almost all the viscous dissipation is lumped,

$y_{\text {lim }, c o}^{+} \quad$ virtual distance from the wall in which almost all the viscous dissipation is lumped for the total mass flow considered as consisting of continuum only, -

$y^{+} \quad$ distance from the wall, -

$z \quad$ axial coordinate, $\mathrm{m}$

$\Delta z \quad$ finite of the axial distance, $\mathrm{m}$

Greek

$\alpha \quad$ volumetric fraction, -

$\delta \quad$ boundary layer thickness, $\mathrm{m}$

$\Phi_{c o}^{2} \quad$ Martinelli-Nelson multiplier, -

$\Delta h \quad=h^{\prime},-h^{\prime}, J / k g$ 
$\Delta \tau_{1 d} \quad$ bubble growth time until departure, $s$

$\Delta \tau_{1 w}$ waiting time until the bubble start to grow, $\mathrm{s}$

$\Delta \tau_{13} \quad$ particle relaxation time, $\mathrm{s}$

$\sigma \quad$ surface tension, $N / m$

$\Delta \tau_{\mu e, \infty}$ time interval in which a eddy is in contact with the wall for developed flow, $\mathrm{s}$

$\Delta \tau_{\mu e, \infty}$ time interval in which a eddy is in contact with the wall for non-developed flow, $\mathrm{s}$

$\chi \quad$ Zaichik's reflection coefficient, dimensionless

$\lambda$ thermal conductivity, $\mathrm{W} /(\mathrm{mK})$

$\lambda_{f r} \quad$ local friction coefficient, -

$\lambda_{R T} \quad=\left(\frac{\sigma}{g \Delta \rho_{21}}\right)^{1 / 2}$, Rayleigh -

Taylor instability wavelength, $m$

$\ell_{2}^{t}=\pi \lambda_{R T}$, turbulent length, $m$

$\tau \quad$ time, $\mathrm{s}$

$\xi \quad$ vapor/liquid boundary layer

thickness ratio, $\mathrm{m} / \mathrm{m}$

\section{Indices}

$\infty$ steady, developed flow

c continuum

d disperse

$l \quad$ field $l$

$m \quad$ field $m$

e eddy

1 steam, gas

2 liquid

3 droplets

co considered that the continuum is occupying the total cross section

total total

boiling boiling only

, saturated liquid

" saturated steam

$\eta \quad$ dynamic viscosity of liquid,

$$
\mathrm{kg} /(\mathrm{ms})
$$

$\Pi$ heated perimeter of the

channel over the section $\Delta z$, $\mathrm{m}$

$n b \quad$ nuclide boiling

$\mathrm{fb} \quad$ film boiling

$n c \quad$ natural circulation

$f_{c} \quad$ forced circulation

sp superheating

wall

$\rho$ density, $\mathrm{kg} / \mathrm{m}^{3}$

$(\rho w)_{32}$ droplets deposition mass flow rate, $\mathrm{kg} /\left(\mathrm{m}^{2} \mathrm{~s}\right)$

$\rho_{2} P_{2}^{w, \text { boiling }}$ total amount of turbulence production per unit volume within a boundary layer with thickness $\delta, \mathrm{W} / \mathrm{kg}$

\section{References}

[1] F. V. Dittus and L. M. K. Boelter, Univ. of Calif. Publ. In Engng, Vol 2, No 13, 1930, p. 443.

[2] R. le R. Sani, "Down flow boiling and non-boiling heat transfer in a uniformly heated tube, University of California, URL-9023, ChemistryGen. UC-4, TID-4500 (15th Ed.), 4 January 1960.

[3] K. Rehme, "Convective heat transfer over rod bundles, in Handbook of single-phase convective heat transfer", Eds. Kakac S, Shah RK and Aung W, John Wiley \& Sons, New York etc. (1987). 
[4] N. I. Kolev, "IVA Simulations to the OECD/NRC Benchmarks based on NUPEC BWR Full-size Fine-mesh Bundle Tests", 3th Workshop on OECD/NRC Benchmark based on NUPEC BWR full-size fine-mesh bundle tests (BFBT)-(BFBT-3), Pisa, Italy, 26-27 April 2006.

[5] N. I. Kolev, "Multiphase Flow Dynamics, Vol. 2 Thermal and mechanical interactions", 3nd ed., Springer, Berlin, New York, Tokyo, 2007a.

[6] J. C. Chen, "A correlation for film boiling heat transfer to saturated fluids in convective flow", ASME Publication-63-HT-34, 1963, pp. 2-6.

[7] N. I. Kolev, "The influence of mutual bubble interaction on the bubble departure diameter", Experimental Thermal and Fluid Science, Vol. 8, 1994, pp. 167-174.

[8] R. F. Gaertner, "Distribution of active sites in the nucleate boiling of liquids", Chem. Eng. Prog. Symp. Series, No. 41, Vol. 59, 1963, pp. 52-61.

[9] C. Y. Han and P. Griffith, "The mechanism of heat transfer in nucleate pool boiling", Part I, Bubble initiation, growth and departure, Int. J. Heat Mass Transfer, Vol. 8, 1965, pp. 887-904.

[10] N. I. Kolev, "Multiphase Flow Dynamics, Vol. 3 Turbulence, gas absorption and release, diesel fuel properties", Springer, Berlin, New York, Tokyo, 2007b.

[11] N. I. Kolev, "How accurate can we predict nucleate boiling", Experimental Thermal and Fluid Science, Vol. 10, 1995, pp. 370-378.

[12] H. K. Forster and N. Zuber, "Dynamics of vapor bubbles and boiling heat transfer", AIChE J., Vol. 1, No. 4, 1955, pp. 531-535.

[13] N. Zuber, "Hydrodynamic aspect of boiling heat transfer", U.S. Atomic Energy Commission Rept., AECU - 4439, Tech. Inf. Serv. Oak Ridge, Tennessee, 1959, 2002 June 2-5.

[14] N. I. Kolev, "To the nucleate boiling theory", Nuclear Engineering and Design, Vol. 239, 2009, pp. 187-192.

[15] C. H. Wang and V. K. Dhir Effect of surface wettability on active nucleation site density during pool boiling of water on a vertical surface, ASME Journal of Heat Transfer, Vol. 115, Aug. 1993, pp. 659-669.

[16] N. I. Kolev, "Film boiling on vertical plates and spheres", Experimental Thermal and Fluid Science, Vol. 18, 1998, pp. 97-115.

[17] T. Okkonen et al., "Film boiling on a long vertical surface under high heat flux and water subcooling conditions", Proc. of the 31st Nat. Heat Transfer Conference, Houston, Texas, August 3-6, 1996.

[18] L. Vaeth, "Radiative heat transfer for the transient three phase three component flow model IVA3", Kernforschungszentrum Karlsruhe GmbH, INR, Interner Bericht 32.21.02/10A, INR-1914, PSF-3212, March 1995.

[19] K. Vierow, Integrated steam explosion analysis with VESUVIUS code, $\mathrm{PhD}$ thesis, University of Tokyo, July 1999.

[20] B. B. Mikic and W. Rohsenow, "A new correlation of pool boiling data including the effect of heating surface characteristics", Transactions of the ASME, J. Heat Transfer, vol. 91, may 1969, pp. 245-250. 